\title{
The problem of informed consent in emergency medicine research
}

\author{
B A Foëx
}

\begin{abstract}
The CRASH Trial (Corticosteroid Randomisation After Significant Head injury), which started in April 1999 hopes to answer the question of whether or not there is any benefit to giving high dose corticosteroids after significant head injuries. To do this patients are randomised to receive either the standard care for head injuries, as defined by the receiving hospital, or standard care plus a 48 hour infusion of corticosteroids. This is to be started within eight hours of injury, preferably as soon as possible. As all eligible patients will have a reduced level of consciousness informed consent has been deemed unnecessary. In this review the issue of consent in human experimentation is presented with a special emphasis on the problems faced in emergency medicine research, and the way these have been tackled.

(Emerg Med f 2001;18:198-204)
\end{abstract}

Keywords: ethics; consent; head injury; corticosteroids

The CRASH (Corticosteroid Randomisation After Significant Head injury) Trial started in April 1999. ${ }^{1}$ In essence it is a placebo controlled trial of the use of corticosteroids in the early management of significant head injuries. In view of the study population: patients with acute head injuries, all of whom have a reduction in level of consciousness, it is a no consent trial.

This review will cover the history of consent in both the doctor-patient relationship and in the researcher-subject relationship and recent developments in consent for clinical trails, particularly those that affect research in emergency medicine.

\section{Historical review}

CONSENT IN THE DOCTOR-PATIENT RELATIONSHIP The very basic principles of medical practice date back to the Classical Period and the writings of Hippocrates. The Hippocratic Oath focuses on the physician's duties to his teacher, and then to his patients: to treat them in the best way he can, neither to take advantage of them or do them any harm, to refrain from performing surgery, and to maintain confidentiality. There is no mention of any concept approaching that of consent, or disclosure.

In the writings of Thomas Percival quite the reverse seems to have been considered appropriate: information would often be withheld from patients, for their own good. When the American Medical Association drew up its
Code of Ethics in 1846-1847 the issue of truth telling remained very much at the discretion of the physician.

Consent for surgery began to appear in the 1950s. The term "intelligent consent" first appeared in a court ruling in 1957 in the USA. It was later replaced by the term "informed consent", which only appeared in a court ruling in the United Kingdom in $1981 .^{2}$

Consent is not usually sought for routine treatment or investigations. These are all carried out under the implied consent of seeking medical attention. For investigations, or treatments carrying a greater (but never clearly defined) risk then specific consent is usually required. It is now recognised that this consent should be fully informed. This is clearly a difficult area. Is the risk clearly known? Will it actually help the patient to know the risk of a general anaesthetic for an elective procedure, much less for an emergency operation?

Beauchamp has listed five key elements to be considered in informed consent. ${ }^{3}$

\author{
Box 1 Key elements in informed \\ consent \\ Disclosure \\ Comprehension \\ Voluntariness \\ Competence \\ Consent
}

Each of these is adequately discussed elsewhere. ${ }^{3}$ The legal aspects of informed consent are covered in Consent to treatment in Mason and McCall Smith (pages 244-88). ${ }^{4}$

In terms of medical treatment Beauchamp considers that there may be five circumstances, when the obligation to obtain informed consent may not apply. ${ }^{3}$

\section{Box 2 Exceptional circumstances, when informed consent may not be possible/necessary \\ Public health emergency \\ Medical emergency \\ Incompetence \\ Therapeutic privilege \\ Patient waiver}

Public health emergencies, in this context, are usually epidemics of dangerous contagious diseases. In such circumstances it may be necessary to treat, or vaccinate, or quarantine patients without their consent. This is clearly a 
breach of the individual's autonomy, which is superseded by the needs of the community as a whole.

Providing treatment in an emergency has always been considered appropriate, even if the patient is unable to consent. This has been tested on numerous occasions in law. In a case in 1990 it was determined that, "In the case of unconscious or incompetent adults a doctor will not be acting unlawfully if he or she acts in the patient's best interests" and for this, "The operation or treatments will be in their best interests if, but only if, it is carried out in order to save their lives, or to ensure improvement or prevent deterioration in their physical or mental health."

An incompetent patient may be physically incompetent (unconscious) or mentally incompetent (as a result of a psychiatric condition). Proxy consent may be obtained, if the patient has previously given authority to such effect. Otherwise, treatment is based on the "necessity test", which was developed as a result of $\operatorname{Re} F^{5}$. The "necessity test" means treatment in the best interests of the patient. In England and Wales it is the medical profession that decides the patients' best interests (in Scotland the courts can do this). The test for this is the same as that used in the law of negligence $^{6}$ : best interest as defined by a responsible body of medical opinion. This is summarised in Mason and McCall Smith (page 257, and summarised pages 248-261). ${ }^{4}$

Conversely there may be circumstances in which a patient is legally incompetent, but quite capable of making an informed decision. In such a case it would not be appropriate to proceed without consent.

Therapeutic privilege. This is when a physician withholds information to avoid causing further harm to the patient. It may be argued that in certain cases full disclosure may change the patient's mental state in such a way that the patient would no longer be competent to make a decision. This is very rarely justifiable and is open to abuse. The very basis of full disclosure is to provoke a degree of anxiety, or reflection, by the patient to ensure that the patient does truly consent.

The final condition is that of the patient waiver, when the patient gives up the right to decide.

CONSENT IN RESEARCHER-SUBJECT RELATIONSHIP As the scientific foundations of medicine were being laid at the end of 19th century, so there was increasing interest in testing new treatments and hypotheses. This involved studies using animals, patients, and volunteers. At the turn of the 19th century Walter Reed of the US Army Medical Corps directed the Yellow Fever Commission and initiated a number of studies to determine the mode of transmission of the disease. After some self experimentation by his colleagues volunteers were sought. A rudimentary consent procedure was followed and a scale of remuneration applied (page 130). ${ }^{7}$

Growing evidence of unethical nontherapeutic research in Prussia at the end of 19 th century resulted, in 1900, in a Govern- ment directive banning medical interventions, other than those necessary for diagnosis, treatment, or immunisation, in minors, incompetent adults, or anyone who had not given "unambiguous consent". An explanation of the risks involved was to be given to all subjects. The directive did not have the force of law. In 1931 the Reich government issued further guidelines, which distinguished between therapeutic and non-therapeutic research. Consent was an absolute requirement in nontherapeutic research. In therapeutic research it was desirable unless the new treatment was needed to save life or prevent permanent damage to the health of the patient. ${ }^{8}$

\section{The Nuremberg Code}

The next major advance in the ethics of human experimentation came as a result of the "Doctors Trial" at Nuremberg in 1946-7. In this the first, and most important, of the medical trials, 23 defendants were charged with: (1) The Common Design or Conspiracy; (2) War Crimes; (3) Crimes Against Humanity, and (for some of the defendants only); (4) Membership in a Criminal Organisation. ${ }^{9}$ Counts 2 and 3 were framed in relation to a catalogue of "experiments" performed on the inmates of concentration camps, and to a programme of euthanasia applied to various categories of psychiatric patients, children with congenital abnormalities, and others considered a burden on society.

Fifteen of the defendants in that first trial were found guilty and seven of them were hanged. ${ }^{10}$

The trial raised many issues not the least of which was the fact that no consent had been sought from the majority of the experimental subjects. An example of such consent as was sought was presented in the opening statement of the prosecution. One of the Gypsy women who volunteered to take part in the rewarming of the hypothermia experiment subjects at Dachau stated, "rather half a year in a brothel than half a year in a concentration camp."

As a result of the trial a 10 point code was established to govern the use of human subjects in biomedical research. ${ }^{11}$ The code was to have international standing. ${ }^{12}$ Its primary clause states that, "The voluntary consent of the human subject is absolutely essential". It then expands on this to include the fact that the subject should be legally competent, should be able to exercise free choice, and should be fully informed. Two other clauses deal with the responsibility of the investigator to end the study if, "the experiment is likely to result in injury, disability, or death to the experimental subject", and with the right of the subject to end the experiment. However, the code does allow that, "The experiment should be such as to yield fruitful results for the good of society, unprocurable by other methods or means of study".

Consent was clearly not sought in the barbaric conditions of the concentration camps. Was it always sought in other parts of the world, or by those who drew up the code? The answer seems to be no. In the US during 
the second world war many experiments were conducted on prisoners and the inmates of mental institutions without great regard for the consent or the safety of the subjects (briefly summarised in Rothman ${ }^{13}$ ). The investigators in many cases considered that these were carefully designed studies tackling problems of national importance (mostly related to infectious diseases, which were to play a crucial part in the Pacific Theatre of operations). Consent and safety were not considered essential. Young men were being sent into battle: no one was seeking their consent. The inmates of prisons and mental institutions were considered to have a similar obligation in their country's hour of need. "Some people were ordered to face bullets and storm a hill; others were told to take an injection and test a vaccine". ${ }^{13}$

One of the problems of the Nuremberg Code was the very fact that it was born of the horrors of the concentration camps: "It was a good code for barbarians but an unnecessary code for ordinary physician-scientists." ${ }^{\prime 14}$ As a result it was often ignored. ${ }^{15}$ Henry Beecher, in 1966, searched various journals for examples of what he termed "unethical research", which he thought did harm to the good name of American medicine. He found 50 examples of unethical research, only 22 of which were described in detail, and in only two was consent mentioned. ${ }^{16}$

Since the report of the Presidential Advisory Committee on Human Radiation Experiments it is clear that the US Government, through various departments, sponsored many experiments in the postwar period on the effects of radioactivity without obtaining consent. ${ }^{17}$ Many of these were clearly in breach of the Nuremberg Code in that they were performed without consent, they could be of no therapeutic benefit to the subjects or to society, and they exposed the subjects to harm.

The Declaration of Helsinki

The Nuremberg Code was written largely by lawyers (assisted by Andrew Ivy, delegated by the American Medical Association as medical consultant to the Prosecution). The medical profession as a whole only really became involved in the 1950s when the Medical Ethics Committee of the World Medical Association began to propose an ethics policy for research. Draft proposals were published in 1961, which in 1964 became the Declaration of Helsinki. ${ }^{18}$ This was a far more extensive document than the Nuremberg Code, including a general introduction, basic principles, and sections on clinical research, and non-therapeutic clinical research. It recognised that the ethical principles that apply to non-therapeutic research also apply when experimentation is combined with clinical care. In contrast with the Nuremberg Code consent was not pre-eminent: it did not appear in the "Basic principles". The Declaration urged that in clinical research combined with professional care then consent should be obtained, "if at all possible". It was only in the section on "Non-therapeutic clinical research" that the issue of consent was given prominence, but only as the third principle. Accord- ing to the Declaration in cases of legal, or physical incapacity consent could be provided by the legal guardian.

Helsinki, with its distinction between therapeutic and non-therapeutic research, was generally regarded favourably by the medical profession: "It is an ethical as opposed to a legalistic document and is thus a more broadly useful instrument than the one formulated at Nuremberg", Henry Beecher, quoted in Annas and Grodin. ${ }^{19}$

In 1975 the Declaration was revised. The list of basic principles was expanded from 5 to 12 , and this time consent appeared as a "basic principle", albeit only the ninth. Another interesting change occurred in the section on clinical research. Principle 5 stated that, "If the doctor considers it essential not to obtain informed consent, the specific reasons for the proposal should be stated in the experimental protocol for transmission to the independent committee." A further distancing from the primacy of consent, in favour of medical judgement.

In 1975 the Declaration countenanced minors as research subjects. Principle 11 stated, "When the subject is a minor, permission from the responsible relative replaces that of the subject in accordance with national legislation. The possibility of a minor being able to give consent was incorporated into the 1983 revision of the Declaration: “The minor's consent must be obtained in addition to the consent of the minor's legal guardian".

The Declaration was further revised in 1996, in South Africa. ${ }^{20}$ More recently a European Bioethics Convention was signed in 1997 (but not by the UK or Germany). ${ }^{21}$

It has been argued that the very distinction between therapeutic and non-therapeutic research is now out of date and that the wording of the Declaration results in regular violations. $^{22}$ Such sentiment prompted a draft revision of the Declaration of Helsinki, which was presented at the World Medical Association Council meeting in Chile in $1999 .{ }^{23}$ It was greeted with considerable misgiving. The Bulletin of Medical Ethics declared that, "To change it [the Declaration of Helsinki] completely, for the sake of a small bunch of American researchers who want greater freedom to behave unethically, might destroy all its value", ${ }^{24}$ while the Lancet proclaimed that, "This redraft of Helsinki is a declaration with little declare". ${ }^{25}$ A less strident note was sounded by Brennan, who wrote that, "The proposed revisions to the Declaration of Helsinki weaken the principle of the researchers moral commitment to the research subject and provide diminished protection of the rights of research subjects". ${ }^{26}$ The potential benefits, and consequences, of the proposed revisions were summarised in the August 1999 issue of the Bulletin of Medical Ethics, to which readers are directed for detailed analysis.

CONSENT IN CLINICAL TRIALS

Now we are in the era of "evidence-based medicine" it has become clear that in many areas of medicine, especially emergency 
medicine, there is very little real evidence to support some of the treatments routinely used. To obtain evidence requires randomised clinical trials, for which patients must give consent. There is an interesting paradox that a new treatment may be instituted almost at the whim of the clinician treating the patient, but if the clinician wishes to perform a trial of the efficacy of that treatment consent must be sought. ${ }^{27} 28$

While consent has featured in both the Nuremberg Code and the Declaration of Helsinki it has not always been regarded as essential by researchers. Hill, one of the pioneers of postwar clinical trials in the UK, strongly resisted the assumption that consent was mandatory. ${ }^{29}$

Consent becomes more complicated in the setting of the emergency department or the intensive care unit. Many of the patients are not in a position to give consent. A number of solutions to this problem have been devised.

\section{Consent by proxy}

This is when consent is sought from the next of kin, or another family member. This has intuitive appeal: the next of kin should have the best interests of the patient at heart, and was included in the Declaration of Helsinki. ${ }^{18}$ However, under English law it is clear that no one can give consent on behalf of another adult. ${ }^{30}$ Hughes concluded that, "No one, not even a court, can give consent on behalf of an incompetent adult patient, and this, by definition, includes the wife ...". ${ }^{30}$

The situation can be summarised as, "Proxy consents are truly valid only when the patient has given express authority to another person to give or withhold consent on his behalf or when the law invests a person with such power."(page 248). ${ }^{4}$ It is by this mechanism that parents may take decisions for their children. The power of proxy has to be exercised "reasonably", something that is hard to define.

\section{Deferred or retrospective consent}

Regulations established in the USA by the Department of Health and Human Services (DHHS) in July 1981 required all studies with human subjects be approved by an institutional review board (IRB), and fulfil three basic conditions. The risks to the subject must be outweighed by benefit to the subject, and knowledge gained, the rights and welfare of subjects must be protected, and, "legally effective informed consent will be obtained by adequate and appropriate methods". This prompted the comment, "The application of these requirements to emergency resuscitation research creates a conflict that threatens to impede such research unless a solution can be found." 31

Within a few years the concept of deferred consent had been put forward. ${ }^{32}$ This relied on obtaining consent from the patient (or a representative) after the event: it was in essence consent to remain within the study. This was clearly a breach of patient autonomy: an intervention was performed without specific con- sent, but it was regarded as an acceptable compromise by investigators and patients and their relatives. ${ }^{33}$ This practice has since been rejected by the US Food and Drug Administration. ${ }^{34}$

Waived consent, or no consent

Both the FDA and the DHHS recognised that there were exceptional circumstances, when experimental treatments might be given to patients with life threatening conditions. These were summarised by Abramson et al. . $^{32}$ However, it was clear that these exemptions from the requirement for informed consent were not directly applicable to randomised trials, although they were, on occasion, used for the purpose. This seems to have been the basis for the Houston study comparing immediate and delayed fluid resuscitation for hypotensive patients with penetrating torso injuries: "A policy of waived consent, which adhered to the principal (sic) of implied consent, was approved . . . This waiver of informed consent followed guidelines specified by federal regulation". ${ }^{35}$

In 1996 new regulations were put forward specifically to tackle the problem of research in emergency situations. ${ }^{36}$ These list the conditions that must be met before research can be carried out without consent. These conditions have been disseminated and discussed. ${ }^{37} 38$

The concept is very simple: because many of the patients will be unable to give consent, and because the trial is in a setting of critical care and there is no evidence that either arm of the study carries a greater risk than the other, then consent is not fundamentally necessary. It is a reversal of the trend to absolute autonomy of the patient in favour of the paternalistic approach to medicine.

Recent studies, for which informed consent was not sought have aroused considerable controversy. ${ }^{39}$ A study of the HIV status of patients admitted to an intensive care unit in South Africa was conducted without consent. ${ }^{40}$ This was criticised as being unethical, even racist, ${ }^{41}$ but was defended by the ethical committee, which approved the study. ${ }^{42}$

The authors defended their actions on the grounds that the study met with four standards for research without consent: (1) It is impossible to obtain informed consent; (2) The research is of sufficient importance that patients' right to informed consent may be waived; (3) There must be unanimous agreement among appropriate individuals and groups that the aforementioned conclusions are valid; (4) Every attempt must be made to protect patients' interests after enrolment. ${ }^{43}$

A study, which evaluated the effect of a stroke family care worker, sought consent from patients to enter the study, but did not seek consent to randomise them to the intervention or the standard therapy group. ${ }^{44}$ The authors' grounds for omitting this from the consent procedure was that: (1) There was no expectation of harm from the randomisation; (2) Patients could refuse to continue at any time; (3) It was thought that if patients knew about the care worker and were then randomised to standard care they might be demoralised and 
Box 3 Waiver of informed consent requirements in certain emergency research (adapted from the Federal Register ${ }^{36}$ )

1 The human subjects are in a life threatening situation

(i) available treatments are unproven or unsatisfactory

(ii) scientific evidence is needed on the safety and effectiveness of particular interventions (this may include randomised placebo controlled trials)

2 Obtaining informed consent is not feasible because:

(i) their medical condition prevents it

(ii) the intervention must be administered before consent can be obtained from the subject's legally authorised representative (LAR)

(iii) individuals likely to become eligible for participation cannot be identified prospectively

3 Participation in the research holds out the prospect of direct benefit to the subjects because:

(i) subjects are in a life threatening situation necessitating intervention

(ii) there is evidence (animal or pre-clinical) to suggest that there may be a benefit from the intervention

(iii) the risks associated with the research are reasonable in relation to the clinical situation, the risks and benefits of standard therapy, and the risks and benefits of the intervention, if known

4 The research could not practicably be carried out without the waiver

5 The proposed research protocol defines the length of the potential therapeutic window based on scientific evidence. Within that time the investigator should attempt to contact and obtain consent from an LAR, if consent cannot be obtained from the subject. Such efforts should be documented for future review by the IRB

6 The IRB has reviewed and approved informed consent procedures and an informed consent document to be used when consent can be obtained

7 Additional protection of the rights and welfare of the subjects will be provided, including at least:

(i) consultation with community representatives

(ii) disclosure of the proposed research, and any associated risks, to the community from which subjects will be drawn

(iii) disclosure of sufficient information after completion of the research to apprise the community, and researchers, of its results

(iv) the establishment of an independent data monitoring committee to exercise oversight of the research

(v) attempts to contact and obtain consent from an LAR, if consent cannot be obtained from the subject. Such efforts should be documented for future review by the IRB

8 The IRB will ensure that there are procedures to:

(i) inform the subject, or an LAR, at the earliest opportunity, of his inclusion in the research

(ii) provide all the information in the consent document

(iii) allow the subject, or an LAR, to withdraw from the research without any penalty

(iv) if the subject dies before an LAR has been contacted information about the research should be provided to the LAR

so bias the result of the study. ${ }^{44}$ This did not go unchallenged..$^{45}$ In essence, in both of these studies, the results were considered to justify the means.

Children and incompetent adults

There are two more instances that deserve consideration: children and incompetent adults. It is well recognised that young children cannot give consent. It used to be taken for granted that parents needed to give consent for any of their children under the age of 16 years. The increasing maturity of young children means that now the concept of an age limit is no longer appropriate. Instead there is now the concept of "Gillick competence", which arose out of an action against West Norfolk and Wisbech Area Health Authority over the provision of contraception to a child under the age of 16 years, without the consent of her parents. ${ }^{46}$ It was decided that the parental right to determine the treatment of such a child "terminates if and when the child achieves a significant understanding and intelligence to enable him or her to understand fully what is proposed". ${ }^{47}$ Consent and incompetent adults has been alluded to above, and is ably covered by Mason and McCall Smith (248-61). ${ }^{4}$

\section{Discussion}

A British perspective is provided by Doyal, who in 1997, suggested that journals should not publish research to which patients had not given fully informed consent- - with three exceptions. ${ }^{48}$ These were: (1) Patients incompetent to give consent (children, adults with learning difficulties, unconscious/semiconscious patients in a critical care situation); (2) Use of medical records (the issue is the degree of this wrong in light of the potential benefit...provided that confidentiality is maintained and no further active involvement is expected); (3) Stored tissue from anonymous donors.

Collins et al argued strongly, based on their experience with the ISIS-2 Trial, that the ethics of randomised trials should be no different to 
the ethics of routine medical care. ${ }^{49}$ Their arguments were summarised in five points (box 4).

Box 4 The lessons of ISIS-2 ${ }^{49}$

(1) Large simple trials save many lives

(2) As long as trials are governed by the "uncertainty principle", there is an approximate parallelism between good science and good ethics, so there is no pressure to be any more unethical than ordinary medical practice is.

(3) Excessively detailed consent may severely damage recruitment, causing (directly or indirectly) many deaths.

(4) Excessively detailed consent may also be distressing and inhumane.

(5) Patients do not cease to be human when considered for trials, so the degree of informed consent that is humanly appropriate in routine medical treatment outside trials may not differ greatly from that which is humanly appropriate in a randomised comparison of different treatments that is governed by the uncertainty principleor, to use Professor Baum's phase, "double standards are not appropriate". ${ }^{50}$

Where does all this leave the CRASH study? By its very nature the study involves patients with a depressed level of consciousness, who may be regarded as incompetent to give informed consent. It therefore falls into one of Doyal's exceptions to the requirement for informed consent. It would seem to meet the four standards alluded to by Bhagwanjee, if we assume that there is widespread agreement that potential improvements in the management of significant head injuries is, "research (is) of sufficient importance that patients' right to informed consent may be waived". ${ }^{43}$ The study also meets the first five of the waiver requirements from the US Department of Health and Human Services (see box 3). The CRASH study information pack does suggest that researchers obtain verbal consent from patients or their families, when possible, but no consent document has been established (point 6). The aspects of point 7 relating to community involvement are not clearly defined, which makes them difficult to apply in any sense other than by gaining approval from a local ethics committee. Point 8 has not been specifically resolved but arrangements could be made to ensure compliance.

\section{Conclusions}

In 1966 Henry Beecher wrote that, "An experiment is ethical or not at its inception; it does not become ethical post hoc-ends do not justify means. There is no ethical distinction between ends and means." 16 The scope of medicine has changed since 1966. It is clear that to continue developing emergency medicine good quality evidence is needed. It would be equally unethical to deprive patients of perfectly good new treatments because of, "Un- necessary obstacles to randomisation or to large numbers (which) may lead to many thousands of future patients being inappropriately treated". 49

There are circumstances when it will be impossible to reconcile the doctrine of informed consent and the practical necessities of research. As long as researchers adhere to the "uncertainty principle", described by Collins et $a l,{ }^{49}$ and sufficient safeguards are in place (such as those in box 3), then to some extent we may have to accept the consequentialist ethic that, "the ends justify the means".

Funding: none.

Conflicts of interest: the author has enrolled a number of patients in the CRASH Trial.

1 Yates D, Farrell B, Teasdale G, et al. Corticosteroids in head injury-the CRASH trial. $\mathcal{F}$ Accid Emerg Med 1999;16:83-4. Chatterton v Gerson [1981] QB 432, [1981] All ER 257.

3 Beauchamp T. Informed consent. In: Veatch R, ed. Medical ethics. 2nd ed. Sudbury, MA: Jones and Bartlett Publishers,
endical 1997:185-208.

4 Mason J, McCall Smith R, Laurie G. Law and medical ethics. 5th ed. London: Butterworths, 1999.

5 Re F 19902 AC, [1989] 2 All ER 545

6 Bolam v Friern Hospital Management Committee [1957] 2 All ER 118, [1957] 1 WLR 582.

7 Jonsen A. The birth of bioethics. New York: Oxford University Press, 1998.

8 Vollmann J, Winau R. Informed consent in human experimentation before the Nuremberg code. BMf 1996; 313:1445-7.

9 Taylor T. Opening statement of the prosecution, December 9, 1946. In: Annas G, Grodin M, eds. The Nazi doctors and the Nuremberg Code. Human rights in human experimentation. New York: Oxford University Press, 1992:67-93.

10 Mitscherlich A, Mielke F. Doctors of infamy. The story of the Nazi medical crimes. New York: Henry Schuman, 1949.

11 Annas G, Grodin M. The Nazi doctors and the Nuremberg Code. Human rights in human experimentation. New York: Oxford University Press, 1992:371.

12 Drinan R. The Nuremberg principles in international law. In: Annas G, Grodin M, eds. The Nazi doctors and the Nuremberg Code. Human rights in human experimentation. New York: Oxford University Press, 1992:174-82.

13 Rothman D. Ethics and human experimentation. Henry Beecher revisited. N Engl f Med 1987;317:1195-9.

14 Katz J. The consent principle of the Nuremberg Code: its significance then and now. In: Annas G, Grodin M, eds. The Nazi Doctors and the Nuremberg Code. New York: Oxford University Press, 1992:227-39.

15 Anon. Ethics of human experimentation. (Editorial). BMf 1963;2:1-2.

16 Beecher H. Ethics and clinical research. N Engl f Med 1966; 274:1354-60.

17 Josefson D. US compensates subjects of radiation experiments. BMF 1996;313:1421.

18 World Medical Association. Human experimentation. Code of ethics of the World Medical Association. BMF 1964;2:177

19 Annas G. The Nuremberg Code in US courts: ethics versus expediency. In: Annas G, Grodin M, eds. The Nazi doctors and the Nuremberg Code. Human rights and human experimentation. New York: Oxford University Press, 1992: 201-22.

20 World Medical Association. World Medical Association Declaration of Helsinki. $\mathcal{F A M A}$ 1997;277:925-6.

21 Watson R. European bioethics convention signed. BMf 1997;314:1066.

22 Levine R. The need to revise the Declaration of Helsinki. $N$ Engl F Med 1998;341:531-4.

23 World Medical Association. Proposed revision of the Declaration of Helsinki. Bull Med Ethics 1999;April:18-22.

24 Editorial. Helsinki Declaration revising continues. Bull Med Ethics 1999;March:3-5.

25 Anon. Declaration of Helsinki-nothing to declare? Lancet 1999;353:1285.

26 Brennan T. Proposed revisions to the Declaration of Helsinki: will they weaken the ethical principles underlying human research? N Engl F Med 1998;341:527-31.

27 Smithells R. Iatrogenic hazards and their effects. Postgrad Med F 1975;51:39-52.

28 Truog R, Robinson W, Randolph A. Is informed consent always necessary for randomized, controlled trials? $N$ Engl f Med 1999;340:804-7.

29 Hill A. Medical ethics and controlled trials. BMF 1963;1: 1043-9.

30 Hughes J. No one can give consent on behalf of an incompetent adult patient. $B M \mathcal{F}$ 1996;313:1477.

31 Abramson N, Meisel A, Safar P. Informed consent in resuscitation research. $\mathcal{F A M A}$ 1981;246:2828-30. 32 Abramson N, Meisel A, Safar P. Deferred consent. FAMA 
33 Abramson N, Safar P. Deferred consent: use in clinical resuscitation research. Ann Emerg Med 1990;19:781-4.

34 Mariner W. Research in emergency care without consent: new proposed FDA rules. Lancet 1995;346:1505-6.

35 Bickell WH, Wall MJ, Pepe PE, et al. Immediate versus delayed fluid resuscitation for hypotensive patients with penetrating torso injuries. N Engl f Med 1994;331:1105-9. 36 National Institutes of Health $\mathrm{H}$. Waiver of informed consen requirements in certain emergency research. Federal Register 1996; 61:51531-3

37 Food and Drug Administration. Protection of human subjects: informed consent. Bull Med Ethics 1997; October: $9-11$.

38 Wichman A, Sandler A. research involving critically ill subjects in emergency circumstances: new regulations, new challenges. Neurology 1997;48:1151-77.

39 Smith R. Informed consent: the intricacies. BMf 1997;314: 1059-60.

40 Bhagwanjee S, Muckart D, Jeena P, et al. Does HIV status influence the outcome of patients admitted to a surgical influence the outcome of patients admitted to a surgical intensive care unit?

41 Kale R. Commentary: Failing to seek patients' consent to research is always wrong. BMf 1997;314:1081-2.
42 Seedat Y. Commentary: No simple and absolute ethical rule exists for every conceivable situation. BMF 1997;314: exists for

43 Bhagwanjee S, Muckart D, Jeena P, et al. Commentary: Why we did not seek informed consent before testing patients for HIV. BMF 1997;314:1082-3.

44 Dennis M, O'Rourke S, Slattery J, et al. Evaluation of a stroke family care worker: results of a randomised controlled trial. BMF 1997;314:1071-7.

45 McLean S. Commentary: No consent means not treating the patients with respect. BMF 1997;314:1076.

46 Gillick v West Norfolk and Wisbech Area Health Authority [1986] AC 112, [1985] 3 All ER 402, HL

47 All 402 at 423, per Lord Scarman.

48 Doyal L. Journals should not publish research to which patients have not given fully informed consent - with three exceptions. BMF 1997;314:1107-11.

49 Collins R, Doll R, Peto R. Ethics of clinical trials. In: Williams C, ed. Introducing new treatments for cancer: practical, ethical and legal problems: Chichester: John Wiley, 1992: cal, ethical

50 Baum M. Do we need informed consent? Lancet 1986;ii: 911-12. 